\title{
Ischemic modified albumin increases in acute kidney injury
}

\author{
Cuma Mertoglu ${ }^{1 *}$, Murat Gunay ${ }^{1}$, Ali Gurel ${ }^{2}$, Mehmet Gungor $^{3}$, Vahdet Gul ${ }^{1}$ \\ 1. Department of Clinical Biochemistry, Faculty of Medicine, Erzincan University, Erzincan, Turkey \\ 2. Department of Nephrology, Mengucek Gazi Training and Research Hospital, Erzincan, Turkey \\ 3. Department of Clinical Biochemistry, Sivas State Hospital, Sivas, Turkey
}

\begin{abstract} were compared. ratio, mean platelet volume

\section{Introduction}

Acute kidney injury (AKI) is a serious kidney disease carrying high morbidity and mortality (1). Many factors including ischemic reperfusion injury, inflammation, hypoxia and oxidative stress play a central role in the physiopathology of AKI (2-4). Oxidative stress is defined as tilting the balance between antioxidant defence mechanisms and attacks of free radicals in favour of free radicals (5).
\end{abstract}

Purpose: Acute kidney injury (AKI) is a severe kidney disease carrying high morbidity and mortality. An ischemic process, at the cellular level, has been detected prior to the full-blown AKI. An elevated ischemic modified albumin (IMA) was also found to be increased fast at several minutes following an ischemic process in the body. In this connection, we have investigated, in advance, the changes of IMA concentrations in patients with possible AKI.

Methods: IMA and other biochemical and haematological parameters were measured in sera of thirty nine patients with AKI and of thirty eight healthy controls. AKI is defined by an increase in serum creatinine by $\geq 0.3$ $\mathrm{mg} / \mathrm{dl}$ in 48 hours or an increase by $\geq 1.5$-fold from a known or assumed baseline. The results in the two groups

Results: IMA, creatinine, blood urea nitrogen, white blood cell, neutrophil, neutrophil-lymphocyte ratio $(N L R)$, platelet-lymphocyte ratio (PLR) and mean platelet volume were found to be higher in patients with AKI than in healthy controls. In contrast, total protein, albumin, lymphocyte, and haemoglobin were lower in patients with AKI than in healthy controls. No significant difference was recorded in platelet counts between the two groups.

Conclusion: Our results indicate that increased levels of NLR and PLR play a central role in a systemic inflammation in AKI. Monitoring serum IMA could be a useful tool in the assessment of AKI.

Keywords: Acute kidney injury, ischemic modified albumin, neutrophil-lymphocyte ratio, platelet-lymphocyte

Received: 23 ${ }^{\text {rd }}$ May 2017; Accepted: 19 ${ }^{\text {th }}$ November 2017; Published: $16^{\text {th }}$ December 2017

AKI is usually diagnosed according to the elevation of creatinine in plasma. Although creatinine is a nonspecific marker, its level in plasma is affected by various variables including age, gender, muscle mass and hepatic functions. It takes many days to rise until the loss of ca. $50 \%$ of glomerular functions $(6,7)$. It is, therefore, inevitable to search new markers pinpointing a possible AKI in advance $(8,9)$. These include neutrophil gelatinase-associated lipocalin (NGAL) (10), Interleu-

\footnotetext{
*Corresponding author: Cuma Mertoglu, Erzincan Universty, Erzincan, Turkey.
}

E-mail: drcumamert@hotmail.com 
kin (IL)-18 (11), kidney injury molecule-1 (KIM1), insulin-like growth factor binding protein 7 (IGFBP7) and tissue inhibitor of metalloproteinase 2 (TIMP-2) (12). NGAL is one of the most promising among others (13).

Cell membrane integrity is damaged and disrupted by free radicals modifying binding capacity of heavy transition metals such as nickel and cobalt at the amino terminal ends of albumin structure. The newly formed albumin with reduced binding capacity to these metals is called ischemic modified albumin (IMA) (14). As a result of an ischemic process, increased levels of IMA have been detected in patients with ischemic heart disease, end-stage renal disease and perinatal asphyxia (15-17). Some other diseases caused by ischemia give rise to elevated IMA concentration (18).

IMA is the only laboratory test approved by the Food and Drug Administration in U.S.A. for ischemia (19). The level of IMA begins to rise in 3 hours in plasma following an ischemic process. It peaks first in 24 hours and reduces gradually in several days to normal levels (20).

Two new tests were also recommended as inflammatory biomarkers. These are neutrophil-to-lymphocyte ratio (NLR) and platelet-to-lymphocyte ratio (PLR) $(21,22)$. We, therefore, included, these two parameters to this study for further investigation.

An increased mean platelet volume (MPV) was suggested as an important indicator of platelet activity in associations with inflammatory process, high platelets turnover and increased vascular damage (23). In this regard, we looked at the changes of MPV in association with inflammation in patients with AKI and healthy controls.

\section{Material and methods}

This study was carried out between December 2015 and June 2016 in our hospital nephrology and emergency out-patient clinics. A total of 39 patients (age span $18-70$ years old) with AKI (19 females 20 males) and 38 healthy controls (18 females and 20 males) were included in this study. The study protocol was approved by the Erzincan University Clinical Etics Committee (number: 33216249-604.01.02-E.20063). All authors confirmed in writing that they have complied with the World Medical Association Declaration of Helsinki regarding ethical conduct of research involving human subjects. Written informed consent was obtained from all the participants.

\section{Exclusion criteria}

Patients known to have chronic kidney disease, myocardial infarct, sepsis, acute respiratory distress syndrome, diabetes mellitus, rheumatic diseases, cardiovascular system disorders were excluded from this study as IMA level is affected by these conditions.

\section{Definition of AKI}

"AKI is defined by an increase in serum creatinine by $\geq 0.3 \mathrm{mg} / \mathrm{dl}$ in 48 hours or an increase by $\geq 1.5$-fold from a known or assumed baseline (24). As a baseline creatinine level, we used the values belonging to patients who had been previously examined in the hospital Biochemistry Central Laboratory at any time and for any reason.

\section{Laboratory process}

The serum samples were kept at $-80{ }^{\circ} \mathrm{C}$ after centrifugation until biochemical tests were performed. Full blood counts were carried out on fresh blood by using Sysmex XN-1000 automatic haematology analyser (Sysmex Corporation, Kobe, Japan). Serum creatinine, BUN, total protein and albumin concentrations were measured by Beckman Coulter Olympus AU2700 auto-analyser. NLR and PLR values were calculated for the two groups. The levels of IMA were measured by using ELISA (Cusabio ${ }^{\circledR}$ Human IMA ELISA Kit). The results were reported as IU/ml. 


\section{Statistical analysis}

The data were analysed using Excel (Microsoft) and MedCal. Descriptive statistics (mean, median, standard deviation, minimum, maximum, number) were generated for patients and healthy subjects. The normality assumption was checked using the Kolmogorov-Smirnov test. Differences between the two groups were evaluated by the independent t-test when the assumptions of this parametric test were met. Mann-Whitney U test was used for the data with an abnormal distribution. A chi-square test was undertaken to evaluate the difference between the groups concerning the categorical variables. The $p$-value of $<0.05$ was considered statistically significant.

\section{Results}

There were no differences for gender, weight and height between patients and control groups, but the mean age was higher in the patients' group than in the healthy subjects (Table 1). BUN, creatinine, IMA, white blood cell (WBC), neutrophil, MPV, NLR and PLR values were found significantly higher in patients with AKI, whereas, total protein, albumin, haemoglobin and lymphocyte were found to be lower in AKI patients than in healthy controls. The platelet count was not different between the two groups (Table 2). The following values were calculated as $51.5(\mathrm{IU} / \mathrm{mL})$ for the IMA cutting value, 53.8 for sensitivity,78.9 for specificity, 0.666 for the area under curve, 0.543 to 0.774 for the $95 \%$

\section{Table 1. Comparison of demographic data of acute kidney injury and control groups.}

\begin{tabular}{cccc}
\hline $\begin{array}{c}\text { Demo- } \\
\text { graphic } \\
\text { data }\end{array}$ & $\begin{array}{c}\text { Control } \\
(\text { mean } \pm \text { SD) }\end{array}$ & $\begin{array}{c}\text { AKI } \\
(\text { mean } \pm \text { SD) }\end{array}$ & p- value \\
\cline { 1 - 3 } Age & $41 \pm 15$ & $66 \pm 19$ & $<0.001 \mathrm{a}$ \\
\cline { 1 - 3 } Female $(\%)$ & $18(47.3)$ & $19(48.7)$ & \\
\cline { 1 - 3 } Male (\%) & $20(52.7)$ & $20(51.3)$ & 0.9127 \\
\hline Weight $(\mathrm{kg})$ & $72.4 \pm 11.3$ & $71 \pm 10.6$ & 0.5895 \\
\hline Length $(\mathrm{cm})$ & $165.3 \pm 5$ & $167.9 \pm 9$ & 0.1724 \\
\hline $\mathrm{a} ; \mathrm{p}<0.0001$ & & &
\end{tabular}

Table 2. Comparison of biochemical and hematologic data between acute kidney injury and control groups.

\begin{tabular}{lccc}
\hline Parameter & Control $($ mean \pm SD) & AKI $($ mean \pm SD) & p-value \\
\hline BUN $(\mathrm{mg} / \mathrm{dL})$ & $24.8 \pm 7.6$ & $129.3 \pm 85.1$ & $<0.0001^{\mathrm{a}}$ \\
\hline Creatinine $(\mathrm{mg} / \mathrm{dL})$ & $0.9 \pm 0.1$ & $3.0 \pm 1.5$ & $<0.0001^{\mathrm{a}}$ \\
\hline Total protein $(\mathrm{g} / \mathrm{dL})$ & $7.14 \pm 0.56$ & $6.67 \pm 0.73$ & $0.0039^{\mathrm{b}}$ \\
\hline Albumin $(\mathrm{g} / \mathrm{dL})$ & $4.23 \pm 0.33$ & $3.57 \pm 0.62$ & $<0001^{\mathrm{a}}$ \\
\hline IMA $(\mathrm{IU} / \mathrm{mL})$ & $39 \pm 21.4$ & $58 \pm 32.6$ & $0.0035^{\mathrm{b}}$ \\
\hline WBC $\left(\mathrm{x} 10^{3} / \mathrm{mm}^{3}\right)$ & $7.9 \pm 1.5$ & $9.3 \pm 3.3$ & $0.013^{\mathrm{b}}$ \\
\hline Hemoglobin $(\mathrm{g} / \mathrm{dL})$ & $13.7 \pm 1.8$ & $12.4 \pm 2.7$ & $0.0081^{\mathrm{b}}$ \\
\hline Platelet $\left(\mathrm{x} 10^{3} / \mathrm{mm}^{3}\right)$ & $284 \pm 10$ & $272 \pm 131.9$ & 0.5547 \\
\hline Neutrophil $\left(\mathrm{x} 10^{3} / \mathrm{mm}^{3}\right)$ & $4.8 \pm 1.4$ & $6.2 \pm 2.8$ & $0.0047^{\mathrm{b}}$ \\
\hline Lymphocyte $\left(\mathrm{x} 10^{3} / \mathrm{mm}^{3}\right)$ & $2.42 \pm 0.5$ & $1.57 \pm 0.9$ & $<0.0001^{\mathrm{a}}$ \\
\hline MPV $(\mathrm{fL})$ & $10.3 \pm 0.69$ & $10.8 \pm 1.2$ & $0.0057^{\mathrm{b}}$ \\
\hline NLR & $1.95 \pm 0.71$ & $3.33 \pm 2.32$ & $0.0005^{\mathrm{b}}$ \\
\hline PLR & $113.7 \pm 28$ & $181.4 \pm 107$ & $0.0001^{\mathrm{c}}$ \\
\hline
\end{tabular}

$\mathrm{a} ; \mathrm{p}<0.0001, \mathrm{~b} ; \mathrm{p}<0.05, \mathrm{c} ; \mathrm{p}=0.0001$. 
confidence interval at the diagnostic point for AKI (Figure 1).

\section{Discussion}

New studies are carried out to search more specific new markers in AKI diagnosis, serum creatinine falling short to meet the criterion of being a specific marker prior to full blown AKI (7). Despite the fact that NGAL, KIM-1, IL- 18, IGFBP7, liver-type fatty acid-binding protein 1 and $N$-acetyl- $\beta$-D-glucosaminidase are relevant in the diagnose of AKI, these parameters were not used routinely to show AKI because of difficulties related to reliability and accuracy in the measurement methods $(7,10-12)$.

In this study, we have shown that IMA could be an important biomarker in AKI diagnosis. It meets the criteria of specificity and sensitivity in AKI diagnosis, especially at the cut-off points of $51.55(\mathrm{IU} / \mathrm{mL})$ (Figure 1).

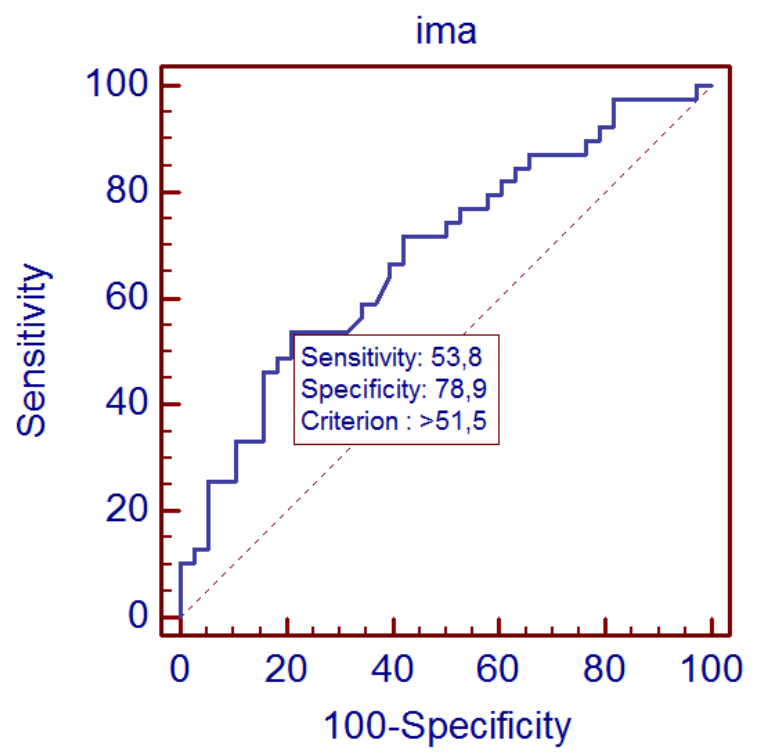

Figure 1. Receiver-operating characteristics (ROC) curve analysis of ischemic modified albumin for the diagnosis of acute kidney injury (area under curve:0.666).
The role of hypoxia and oxidative stress is known in the aetiology of AKI (3). In previous studies, an elevated IMA was demonstrated under the state of hypoxia and oxidative stress $(15,16)$. Our results indicate a strong association between increased IMA and the level of hypoxia and oxidative stress in the process of AKI. Hypoxia is seen in both ischemic and non-ischemic AKI. In response to hypoxia, hypoxia-inducible factor gene is activated in AKI $(3,25)$.

Sharma et al. have suggested that increased IMA associates increased mortality in myocardial infarction in patients with end-stage-renal-disease (ESRD) (16). Kotani et al. found that increased IMA is an important oxidative stress marker in ESRD (18). An increased IMA was also found in post-haemodialysis compared to pre-haemodialysis patients (26). Tilting of the balance between oxygen/nitrogen free radicals and antioxidant defence system is disturbed in favour of free radicals in AKI (4). Similarly, our study has demonstrated that the measurement of IMA could be a useful biomarker in patients with AKI.

It is known that inflammation plays a significant role in the development of AKI, systemic inflammation could be secondary to local kidney inflammation, and systemic inflammation accompanies AKI local injury and may be secondary to kidney inflammation (21). Our results demonstrated significantly increased values of NLR, PLR and MPV in AKI. Y1lmaz et al. (21) have suggested that increased NLR was a predictor of AKI in a serious sepsis. Platelet measurements were found to be similar in both groups. In agreement with our study, they found similar platelet values in both groups, but contrary to our study they found different values WBC to be similar in both groups. The reasoning behind this is that their work is based on a disease characterised by severe inflammation such as sepsis. Hence, their study yielded higher WBC counts $\left(16.7 \pm 5.4\right.$ and $\left.15.9 \pm 5.6 \times 10^{3} / \mathrm{mm}^{3}\right)$ than ours $\left(9.3 \pm 3.3\right.$ and $\left.7.9 \pm 1.5 \times 10^{3} / \mathrm{mm}^{3}\right)$ respectively. 
Previously, two studies $(22,27)$ drew attention to NLR and PLR values as an independent indicator in patients with contrast-induced nephropathy. They also found increased WBC and neutrophils, but a reduced number of lymphocytes, decreased haemoglobin and unchanged platelets in AKI. Our results confirm these data in both studies.

Similar to our results, Han et al. (23) have found high MPV values as an important predictor of mortality in AKI patients requiring continuous renal replacement therapy. Again, they also found a reverse relationship between MPV values and albumin levels. In agreement with this study, we also found lower albumin levels in the AKI group.

This is the first study investigating IMA levels in the diagnosis of AKI. However, in this study, we measured IMA level, while the diagnosis of AKI was made on the basis of creatinine levels (24). However, some early markers (predictors) are known to increase hours before creatinine based diagnosis process in AKI (12). The IMA level begins to rise within minutes of ischemia and peaks after 24 hours (20). Further studies, however, are needed to investigate the early role of IMA in early changes leading to whole blown AKI.

In conclusion, we think that measuring IMA before creatinine increase could be a time-saving method that gives us invaluable time in the early diagnosis of AKI. We think that the measurements of IMA constitute an important place in the diagnosis of AKI. In our forthcoming studies, we are aiming to further investigate the IMA levels in connection with the requirement of dialysis in oliguric and non-oliguric patients in large series. This would enable us to compare AKI in humans and animal models with different aetiology.

\section{Study limitations}

Limitations in our study include, firstly studying a limited number of cases, secondly using only serum creatinine levels as the diagnostic criteria for AKI, and thirdly using only healthy volunteers as the control group.

\section{Research funding}

This study was supported by Erzincan Universty scientific research projects office. The funding organisation played no role in the study design, in the collection, analysis, and interpretation of data, and in the writing of the report, or in the decision to submit the report for publication.

\section{Conflict of interest}

None.

\author{
Abbreviations \\ AKI-Acute kidney injury \\ IMA-Ischemic modified albumin \\ $B U N$-Blood urea nitrogen \\ WBC-White blood cell \\ NLR-Neutrophil-lymphocyte ratio \\ PLR-platelet-lymphocyte ratio \\ NGAL-Neutrophil gelatinase-associated lipoca- \\ lin \\ IL-Interleukin \\ KIM-1-Kidney injury molecule-1 \\ IGFBP7-Insulin-like growth factor binding pro- \\ tein 7 \\ TIMP-2-Tissue inhibitor of metalloproteinase 2 \\ $M P V$-Mean platelet volume
}

\section{References}

1. Chawla LS, Amdur RL, Shaw AD, Faselis C, Palant CE, Kimmel PL. Association between AKI and longterm renal and cardiovascular outcomes in united states veterans. Clin J Am Soc Nephrol. 2014;9(3):448-56. DOI: $10.2215 /$ CJN.02440213

2. Bellomo R, Auriemma S, Fabbri A, D'Onofrio A, Katz $\mathrm{N}$, McCullough PA, et al. The pathophysiology of cardiac surgery-associated acute kidney injury (CSAAKI). Vol. 31, International Journal of Artificial Organs. 2008. p. 166-78. 
3. Nangaku M, Rosenberger C, Heyman SN, Eckardt KU. Regulation of hypoxia-inducible factor in kidney disease. Clin Exp Pharmacol Physiol. 2013;40(2):148-57. DOI: $10.1111 / 1440-1681.12005$

4. Yousefipour Z, Oyekan A, Newaz M. Interaction of oxidative stress, nitric oxide and peroxisome proliferator activated receptor gamma in acute renal failure. Pharmacol Ther. 2010;125(3):436-45. DOI: 10.1016/j. pharmthera.2009.12.004

5. Verma P, Bhattacharya SN, Banerjee BD, Khanna N. Oxidative stress and leukocyte migration inhibition response in cutaneous adverse drug reactions. Indian J Dermatol Venereol Leprol. 2012;78(5):664. DOI: 10.4103/0378-6323.100519

6. Devarajan P. Neutrophil gelatinase-associated lipocalin - An emerging troponin for kidney injury. Vol. 23, Nephrology Dialysis Transplantation. 2008. p. 3737-43. DOI: $10.1093 / \mathrm{ndt} / \mathrm{gfn} 531$

7. Gaut JP, Crimmins DL, Ohlendorf MF, Lockwood CM, Griest TA, Brada NA, et al. Development of an immunoassay for the kidney-specific protein myo-inositol oxygenase, a potential biomarker of acute kidney injury. Clin Chem. 2014;60(5):747-57. DOI: 10.1373/ clinchem.2013.212993

8. Petrica L, Gluhovschi A, Gluhovschi C, Gadalean F, Balgradean C, Groza C, et al. Proximal tubule dysfunction in renal diseases - diagnostic significance of proteomics and biomarkers. Rev Romana Med Lab. 2012;20(2):97-107.

9. Şalaru DL, Macovei L, Stătescu C, Arsenescu-Georgescu C. Assessement of microalbuminuria in hypertensive patients with established coronary artery disease. Rev Romana Med Lab. 2013;21(4):407-14. DOI: 10.2478/rrlm-2013-0041

10. Haase-Fielitz A, Bellomo R, Devarajan P, Story D, Matalanis G, Dragun D, et al. Novel and conventional serum biomarkers predicting acute kidney injury in adult cardiac surgery--a prospective cohort study. Crit Care Med. 2009;37(2):553-60. DOI: 10.1097/ CCM.0b013e318195846e

11. Leslie JA, Meldrum KK. The Role of Interleukin-18 in Renal Injury. J Surg Res. 2008;145(1):170-5. DOI: 10.1016/j.jss.2007.03.037

12. Schrezenmeier E V, Barasch J, Budde K, Westhoff T, Schmidt-Ott KM. Biomarkers in acute kidney injury - pathophysiological basis and clinical performance. Acta Physiol (Oxf). 2016; Disponible: http://www.ncbi. nlm.nih.gov/pubmed/27474473

13. Devarajan P. Neutrophil gelatinase-associated lipocalin: a promising biomarker for human acute kidney injury. Biomark Med. 2010;4(2):265-80. DOI: 10.2217/ bmm.10.12

14. Ellidag HY, Eren E, Yilmaz N, Bayindir A. Ischemia Modified Albumin Levels and Increased Oxidative Stress in Patients With Multiple Myeloma / Nivoi Albu- mina Modifikovanog Ishemijom I Povi[Eni Oksidantni Stres Kod Pacijenata Sa Multiplim Mijelomom. J Med Biochem. 2013;33(2):175-80. DOI: 10.2478/jomb2013-0027

15. Pantazopoulos I, Papadimitriou L, Dontas I, Demestiha T, Iakovidou N, Xanthos T. Ischaemia modified albu$\mathrm{min}$ in the diagnosis of acute coronary syndromes. Vol. 80, Resuscitation. 2009. p. 306-10. DOI: $10.1016 /$ j.resuscitation.2008.10.035

16. Sharma R, Gaze DC, Pellerin D, Mehta RL, Gregson H, Streather CP, et al. Evaluation of ischaemia-modified albumin as a marker of myocardial ischaemia in endstage renal disease. Clin Sci (Lond). 2007;113(1):2532. DOI: $10.1042 / \mathrm{CS} 20070015$

17. Dursun A, Okumus N, Zenciroglu A. Ischemia-modified albumin (IMA): could it be useful to predict perinatal asphyxia? J Matern Fetal Neonatal Med. 2012;25(11):2401-5. DOI: 10.3109/14767058.2012.697943

18. Kotani K, Kimura S, Gugliucci A. Paraoxonase-1 and ischemia-modified albumin in patients with end-stage renal disease. J Physiol Biochem. 2011;67(3):437-41. DOI: $10.1007 / \mathrm{s} 13105-011-0092-4$

19. Sbarouni E, Georgiadou P, Voudris V. Ischemia modified albumin changes - Review and clinical implications. Clin Chem Lab Med. 2011;49(2):177-84. DOI: 10.1515/CCLM.2011.037

20. Shen XL, Lin CJ, Han LL, Lin L, Pan L, Pu XD. Assessment of ischemia-modified albumin levels for emergency room diagnosis of acute coronary syndrome. Int J Cardiol. Elsevier Ireland Ltd; 2011;149(3):296-8.

21. Yilmaz H, Cakmak M, Inan O, Darcin T, Akcay A. Can neutrophil-lymphocyte ratio be independent risk factor for predicting acute kidney injury in patients with severe sepsis? Ren Fail. 2015;37(2):225-9. DOI: 10.3109/0886022X.2014.982477

22. Velibey Y, Oz A, Tanik O, Guvenc TS, Kalenderoglu K, Gumusdag A, et al. Platelet-to-Lymphocyte Ratio Predicts Contrast-Induced Acute Kidney Injury in Patients With ST-Segment Elevation Myocardial Infarction Undergoing Primary Percutaneous Coronary Intervention. Angiology. 2017 May;68(5):419-27. DOI: 10.1177/0003319716660244

23. Han JS, Park KS, Lee MJ, Kim CH, Koo HM, Doh FM, et al. Mean platelet volume is a prognostic factor in patients with acute kidney injury requiring continuous renal replacement therapy. J Crit Care; 2014;29(6):101621. DOI: $10.1016 /$ j.jcrc.2014.07.022

24. Kellum J a, Lameire N, Aspelin P, Barsoum RS, Burdmann E, Goldstein SL, et al. KDIGO Clinical Practice Guideline for Acute Kidney Injury. Kidney Int Suppl. 2012;2(1):1-138.

25. Andringa KK, Agarwal A. Role of hypoxia-inducible factors in acute kidney injury. Nephron - Clin Pract. 2014;127(1-4):70-4. DOI: 10.1159/000363669 
26. Kiyici A, Mehmetoglu I, Karaoglan H, Atalay H, Solak Y, Türk S. Ischemia-modified albumin levels in patients with end-stage renal disease patients on hemodialysis: does albumin analysis method affect albumin-adjusted ischemia-modified albumin levels? J Clin Lab Anal. 2010;24(4):273-7. DOI: 10.1002/jcla.20399
27. Kurtul A, Yarlioglues M, Duran M, Murat SN. Association of Neutrophil-to-lymphocyte Ratio with Contrast-induced Nephropathy in Patients with Non-ST-elevation Acute Coronary Syndrome Treated with Percutaneous Coronary Intervention. Hear Lung Circ. 2016;25(7):683-90. DOI: 10.1016/j.hlc.2016.01.007 